\title{
L. Observations on the growth and on the bilateral symmetry of Echinodermata
}

\section{Agassiz M.D.}

To cite this article: L. Agassiz M.D. (1834) L. Observations on the growth and on the bilateral symmetry of Echinodermata, Philosophical Magazine Series 3, 5:29, 369-373, DOI: $10.1080 / 14786443408648480$

To link to this article: http://dx.doi.org/10.1080/14786443408648480

册 Published online: 01 Jun 2009.

Submit your article to this journal

Џll Article views: 3

Q View related articles $\square$ 
L. Observations on the Growth and on the bilateral Symmetry of Echinodermata. By L. Agassiz, M.D. and Professor of Natural History at Neuchatel.*

THE most general character which has been usually as1 signed to the Echinodermata, is to have all the parts of their body similar to one another, and disposed like rays around a common centre: it is a character in which this class has been supposed to partake with the entire division of $\mathrm{ra}$ diated animals. Nevertheless, on a close examination of this radiated structure, we find that these rays are always dissimilar, but in different degrees in different genera; and that they are not always connected with a centre of the same nature. If we trace the arrangement of parts in the Spatangi, for instance, we are soon led to see that the more or less elongated form of their body is caused by the position of the mouth and the anus, which are placed near the two extremities of the body; and that four of the ambulacral series, and also four of the interambulacral series, are pairs, and symmetrically placed on the two sides of a plane, which, if extended from the mouth to the anus, would divide the animal into two equal parts. The 5 th ambulacral series, and also the 5 th interambulacral series, are single, and not symmetrical. The ambulacral series which passes above the mouth (and which is odd, or not paired,) is consequently the anterior series; whilst the posterior part of the body is occupied by an interambulacral series: it is in the central line between its plates that the anus is placed. We have then in the Spatangi an anterior region, distinguishable by the unequal ambulacral series, and a posterior region, distinguishable by the unequal interambulacral series. On the two sides of the animal the series of plates are disposed in symmetrical pairs, in such a manner that there are two pairs of ambulacral series and two of interambulacral on the right, and two on the left. The first anterior pair, which adjoins the unequal ambulacral series, is a pair of interambulacral series, immediately behind which is placed the first pair of ambulacral series, then a second pair of interambulacral, and lastly, a second pair of ambulacral series. Behind these is the uneven posterior interambulacral series.

As to the Clypeasters, the Galerites, the Nucleolites, \&c., in which the mouth is central and the anus marginal or submarginal, it is nevertheless easy to understand the position of the bilateral parts, because the position of the posterior interambulacral series being given by the position of the anus,

* Communicated by the Author.

Third Series. Vol. 5. No. 29. Nov. 1834. 
there is no difficulty in understanding the symmetrical relations of the other even and odd series. We can always recognise differences in the form of the component plates, and of the ambulacra of the different pairs, which show evidently the appearance of bilateral parity. These, however, are less apparent in the Clypeasters than in the Spatangi. Hence these data become important for the study of the internal soft parts and for the appreciation of their functions.

It might seem that in passing to the Echini and Asterice (simple or ramified), whose mouth is perfectly central, and whose anus, when there is one, is likewise found in the middle, but upper part of the body, there would be no further traces of this bilateral symmetry, and yet even here it is easy to determine the relations of all the radiated parts and of the longitudinal anterio-posterior axis. All the radii of these animals resemble one another so much outwardly, that we might bardly expect to find in their arrangement traces of the bilateral symmetry which is so evident in the Spatangi, \&c. But if we take into account the differences which exist in the structure of the plates of different series, we shall be convinced that here also the symmetry in pairs is maintained under the appearance of a disposition completely radiated; in fact, we find in the upper part of the disk of the Echinodermata, especially in the Echini, the Cidarites, \&c., in the region where the ambulacral and interambulacral series converge, five perforated plates. of peculiar form, which have been called oviducal plates, and are connected with the ovaries, and five interoviducal plates connected with the aquiferous system. The five largest of these plates (the oviducal ones) alternate with the extremities of the ambulacral series; four of these are, therefore, even, and one is odd. That which is odd has a porous particular structure; it is the madreporiform body of the Asterice, which equally exists in the Echini, but under another form: it is always in the posterior region of the body, and when it becomes imperceptible, the space where a lacuna is observed still points out the posterior region of the body, as the madreporiform body of the Asterice shows that the ray opposite to it is the odd anterior ray, whilst the four others are even, and placed on the right and left sides of the animal. The same is the case with the Solasterice, with this difference only, that in them the number of the pairs is more considerable, and that sometimes there is no uneven ray.

In order rightly to comprehend the mode of growth of the Echinodermata, it is necessary to keep in view the general disposition of the solid pieces that constitute their covering: they are plates of greater or less size, disposed in vertical 
zones, diverging from the mouth to the periphery of the body, and converging from thence to the upper centre of the animal. The mouth obviously points out to us the anterior part of the body; but its ordinary position makes it look as if placed in the inferior part of the animal, but in no other respect changes the relations of the parts of the body to one another. We distinguish three principal types in the forms of these animals; some are tubular (the Holothurice), others spheroidal (the Echinoides), and others star-shaped (the Asterides); but they may be reduced to two types, as the tubular form may be viewed in this case as an elongated spheroid: still further, these two types may be reluced to one and the same plan of organization, since the enlargement or multiplication of the ovarial plates at the summits of such a spheroid, and of the plates around the mouth, accompanied by a contraction of the interambulacral plates, would produce a star, whilst, vice versâ, the enlargement of the extreme interambulacral plates, and the contraction of the central plates of a star, would produce a spheroid. 'This is not a mere supposition; the essential difference between the Echini and the Asterice consists in this different mode of increase of parts which are essentially the same. As to the general disposition of the plates in Echinodermata, there are generally twenty series of them, forming ten zones, of which one half are pierced with holes, whilst the other half are entire. The five zones or double series of perforated plates are called the ambulacral series; the others are the interambulacral series. In the Starfish (Asterice) the large plates of the sides of two adjacent radii answer to an interambulacral series of the Echini, whilst each radius has a complete ambulacral series extending from the mouth to the extremity of the radius, and thence back to the upper centre. The middle part of each ambulacral series, or the extreme point of each radius, is consequently the narrowest, and its two ends, or the basis of each radius, the widest. Each radius is, in fact, composed of two parts, resembling two isosceles triangles united by their summits and laid one over another; whereas in the Echini the centre of each series is the widest, and the extremities are the narrowest, like two triangles united by their bases at the equator of the sphere.

With respect to the original relations of all the plates which form these series, we should entertain a false idea if we represented them to ourselves as growing really in that vertical succession which they seem to possess. It is, incleed, at the summits of the series that the new plates are formed, but they succeed each other, like leaves in plants, spirally, from one in- 
terambulacral series to another, so that those which lie in a vertical line one upon another, do not succeed each other in the order of their first growth.

The growth of the plates of Echini takes place chiefly at the upper summit of the shell, and the plates enlarge from the top towards the bottom until they arrive at the greatest circumference of the spheroid, where they become entirely consolidated: at the lower summit, i.e. around the mouth, the growth only takes place during the youth of the animal. Hence arise the differences of form which are observable between the young and the old Echini. In youth they are comparatively flat, and become more and more conical as they advance in age. In the Starfish the new plates are found in the angles of the radii nearest to the upper surface and lower surface of the body; and increasing more and more, they keep carrying to a greater distance the extremity of the radii. Thus, then, the number of the plates is continually increasing, and cannot be employed as a specific character. Hence we see how an Echinus or a Starfish receives its increase, still preserving its essential form and the relative disposition of its parts.

The same system prevails in the structure of the Crinoidea. In their internal organization it is well known that these animals had between their five rays a depression, which no doubt contained their soft organs; but the nature of this cavity is in part unknown, because the interposition of the rays usually obscures the view of their central region; yet after a close examination of many specimens of Briarian Pentacrinite, I have found that the branching rays are disposed around an inclosed cavity, having walls composed of plates distinct from those of the rays. The summit of this pouch presents an aperture surrounded with certain plates stronger than the rest. This aperture is the mouth, with its manducal plates. in many of the Crinoidea, particularly in the Actinocrinites, I have observed on the side of this cavity a second large aperture, placed between two rays of the animal. I consider this to be the anus; if so, this aperture occupies the same place as in the $\boldsymbol{P}$. europaus, and presents a new resemblance to it. These data are sufficient to determine the bilateral disposition of the parts in the Crinoidea, as in the Echini and Asteria, and to point out which of the rays are pairs, and which is the odd ray. The differences which exist between them are so great, that in certain genera, e.g. in the Pentremites and Actinocrinites, they are obvious at the first glance.

As for the genera established in the whole class, I have 
found that the characters drawn from the combination of the plates, and from the disposition of the ambulacra, form divisions more natural and better defined than the characters taken from the position of the mouth and of the anus.

I shall publish my detailed observations upon this subject in a monograph of the Echinodermata, accompanied with plates, for which I have already collected the greater part of the necessary materials.

LI. An Account of a peculiar Optical Phcenomenon seen after having looked at a moving Body, \&c. By R. AdDaMs, Lecturer on Chemistry and Natural Philosophy*.

DURING a recent tour through the Highlands of Scotland, I visited the celebrated Falls of Foyers on the border of Loch Ness, and there noticed the following phænomenon.

Having steadfastly looked for a few seconds at a particular part of the cascade, admiring the confluence and decussation of the currents forming the liquid drapery of waters, and then suddenly directed my eyes to the left, to observe the vertical face of the sombre age-worn rocks immediately contiguous to the water-fall, I saw the rocky surface as if in motion upwards, and with an apparent velocity equal to that of the descending water, which the moment before had prepared my eyes to behold this singular deception.

The cascade is through a depth of about 70 feet, and my position, as I stood when I made the observation, was nearly on a level with the centre of the fall, being the lowest of the two situations where visitors obtain a view of this cupious and never-failing infusion of peat + gushing over the giant step and whitening as it flows. My attention was engaged on that part of the fall which corresponded with a horizontal plane passing through my eye and the water. The sun was masked by cloud at the time.

I am not aware of any existing explanation of this class of optical phænomena, and I may be premature in venturing the following.

I conceive the effect to be owing to an involuntary and unconscious muscular movement of the eyeball, and thus occasioning a displacement of the images on the retina.

Supposing the eyes to be intently gazing at any point in a

- Communicared by the Author.

+ The colour is brown from flowing over peat moors. 